\title{
BMJ Open Factors contributing to the patient safety culture in Saudi Arabia: a systematic review
}

\author{
Abdulmajeed Albalawi (D) , Lisa Kidd, Eileen Cowey
}

To cite: Albalawi A, Kidd L, Cowey E. Factors contributing to the patient safety culture in Saudi Arabia: a systematic review. BMJ Open 2020;10:e037875. doi:10.1136/ bmjopen-2020-037875

- Prepublication history and supplemental material for this paper are available online. To view these files, please visit the journal online (http://dx.doi org/10.1136/bmjopen-2020037875).

Received 19 February 2020 Revised 22 July 2020 Accepted 08 September 2020

Check for updates

(C) Author(s) (or their employer(s)) 2020. Re-use permitted under CC BY-NC. No commercial re-use. See rights and permissions. Published by BMJ.

College of Medical, Veterinary and Life Sciences, Nursing \& Health Care School, University of Glasgow, Glasgow, UK

Correspondence to Abdulmajeed Albalawi; 2282107a@student.gla.ac.uk

\section{ABSTRACT}

Background Patient safety, concerned with the prevention of harm to patients, has become a fundamental component of the global healthcare system. The evidence regarding the status of the patient safety culture in Arab countries in general shows that it is at a suboptimal level due to a punitive approach to errors and deficits in the openness of communications.

Objectives To identify factors contributing to the patient safety culture in Saudi Arabia.

Design Systematic review.

Methods A systematic search was carried out in May 2018 in five electronic databases and updated in July 2020-MEDLINE, CINAHL, Embase, PsycINFO and the Cochrane Database of Systematic Reviews. Relevant journals and reference lists of included studies were also hand-searched. Two independent reviewers verified that the studies met the inclusion criteria, assessed the quality of studies and extracted their relevant characteristics. The Yorkshire Contributory Factors Framework (YCFF) was used to categorise factors affecting safety culture in the included papers.

Results 14 papers were included and the majority of studies were appraised as being of good quality. Strength and weakness factors that contribute to patient safety culture were identified. Ineffective leadership, a blame culture, workload/inadequate staffing and poor communication are reported as the main factors hindering a positive patient safety culture in Saudi Arabia. Conversely, 'strength' factors contributing to a positive patient safety culture included supportive organisational attitudes to learning/continuous improvement, good teamwork within units and support from hospital management for patient safety. There is an absence of patient perspectives regarding patient safety culture in Saudi Arabia.

Conclusion Policymakers in the Saudi healthcare system should pay attention to the factors that may contribute to a positive patient safety culture, especially establishing a blame-free culture, improving communications and leadership capacity, learning from errors and involving patient perspectives in safety initiatives. Further research is required to understand in depth the barriers and facilitators to the implementation of a positive patient safety culture in Saudi Arabia.

\section{INTRODUCTION}

Patient safety culture has become a crucial element within healthcare organisations in

\section{Strengths and limitations of this study}

This is the first systematic review carried out to report factors contributing to patient safety culture in Saudi Arabia.

- This review provides a comprehensive insight into the strengths and weakness factors contributing to patient safety culture in Saudi Arabia.

- This systematic review was restricted to English language publications only and the papers limited to hospital settings only.

- All factors identified in this review are based on the healthcare professionals' perspectives, and factors from patient perspectives remain unknown.

order to prevent patient harm and maintain safe, high-quality healthcare. ${ }^{1}$ Safety culture refers to 'the product of individual and group values, attitudes, perceptions, competencies and patterns of behaviour that determine the commitment to, and the style and proficiency of, an organisation's health and safety management'. ${ }^{2}$ There is growing evidence regarding the effect of strong safety culture on patient safety, patient-related health outcomes and quality of healthcare. ${ }^{3}$ Despite increasing efforts to implement patient safety initiatives worldwide, patient harm represents the 14th leading cause of mortality and morbidity across the world. ${ }^{4}$ The WHO has highlighted that 42.7 million adverse care events are recorded annually worldwide ${ }^{5}$; patient safety is therefore perceived as a serious healthcare issue. Medical errors or harmful incidents involving patients are reported as serious threats to patient safety, because they may affect patients' physical, psychological, emotional and social well-being. ${ }^{5}$ Positive and strong patient safety cultures have been found to significantly reduce the number of adverse events reported in a healthcare organisation. ${ }^{6}$ Improving patient safety culture positively influences and increases the commitment to reporting incidents among healthcare professionals. ${ }^{7}$ Thus, it is believed that higher levels 
of patient safety culture are associated with higher safety performance in healthcare organisations. ${ }^{6}$

A systematic review identified that blame culture and poor communication were common factors associated with a poor patient safety culture in Arab countries, including Saudi Arabia. ${ }^{8}$ Another systematic review shows that there is a communication issue between healthcare providers and patients in Saudi Arabia that leads to preventable errors and poor quality of care. ${ }^{9}$ This deficit in communication was linked to language barriers, workforce diversity and cultural differences. ${ }^{9}$ Fear of being blamed was considered the main barrier to reporting incidence and medication errors among nurses in Saudi Arabia. ${ }^{10}$ In the Saudi Arabian healthcare system, there is an increasing number of complaints and claims against healthcare providers due to mortality or morbidities associated with adverse events. ${ }^{11} 12$ From the sentinel events (defined as unexpected events involving death or serious physical or psychological injury to patients) reported to the Ministry of Health in Saudi Arabia between 2012 and 2015, 91\% were classified as preventable events. ${ }^{13}$

A variety of studies concerned with patient safety culture in Saudi Arabia explore apparent influences on the safety and quality of healthcare services. ${ }^{11} 12$ The vast majority of studies examining patient safety culture in Saudi Arabian healthcare organisations rely on the healthcare providers' perspectives. ${ }^{8}$ Although some evidence highlights that patients offer different perspectives on patient safety compared with healthcare providers, ${ }^{14}$ it is believed that both views are contributing effectively in patient safety that may impact positively on improvement initiatives. ${ }^{15}$ To date, patient views regarding patient safety culture are unknown in Saudi Arabia. Moreover, to our knowledge, no systematic review has evaluated factors contributing to patient safety culture in Saudi Arabia, particularly from different stakeholder perspectives. Thus, the aim of this systematic review was to identify factors contributing to the patient safety culture in Saudi Arabia and explore perspectives on patient safety culture among healthcare professionals and patients in Saudi Arabia.

\section{METHODS}

\section{Protocol and registration}

A protocol for this systematic review was registered on PROSPERO, the international prospective register of systematic reviews under number CRD42018091152.

\section{Search strategy}

In May 2018, five electronic databases were searched (and updated in July 2020)—MEDLINE, CINAHL, Embase, PsycINFO and the Cochrane Database of Systematic Reviews-using Medical Subject Headings (MeSH) and keywords. The key search terms were developed from those of a previous review ${ }^{8}$ and the review question. The search strategy was developed and tested in one electronic database (Medline) and then tailored to the MeSH heading requirements of each database. Search strings for each database are shown in the online supplemental appendix 1. Additionally, bibliographies of included studies, related journals (ie, British Medical Journal (BMJ) Safety and Quality, Journal of Patient Safety), ongoing trials within a clinical trial registry (ClinicalTrials.gov) and ongoing reviews from the PROSPERO website were searched. Findings were exported to Covidence for screening and selection.

\section{Study selection}

Two reviewers (AA) and (LK) independently screened results for relevance to the review question, first by title and abstract and then full-text screening. Discrepancies were resolved by discussion and by a third reviewer (EC), so the studies were selected or excluded based on the following criteria:

\section{Inclusion criteria}

- Empirical studies that investigated perceptions of patient safety, safety culture/climate or the effectiveness of intervention programmes for addressing patient safety in healthcare sectors in Saudi Arabia.

- Study settings that included general hospitals, primary healthcare centres, tertiary hospitals, university hospitals, private hospitals, military and National Guard hospitals.

- Study participants were healthcare professionals, including doctors, nurses, pharmacists, technicians and allied healthcare, or patients, carers and family members.

- All study designs that addressed the phenomena of interest or were relevant to the review question.

- Published in the English language between 2008 and 2018.

\section{Exclusion criteria}

- Studies not conducted in Saudi Arabia.

- Studies conducted in non-healthcare settings or industries.

- Participants not registered as healthcare professionals and were neither patients nor family members.

- Non-empirical descriptive studies (theoretical papers, views, essays, editorials, newspapers and magazine articles).

- Abstracts or posters only.

\section{Data extraction and critical appraisal}

Data extraction and critical appraisal of included studies were conducted by two independent reviewers (AA and LK), with disagreements settled by a third reviewer (EC) as shown in the online supplemental appendix 2 and. ${ }^{34}$ Two tools were used to assess the quality of included studies. First, the version of the Newcastle-Ottawa Scale for crosssectional studies was used for quantitative studies using a cross-sectional design. ${ }^{16}$ This tool has been used in previous reviews. ${ }^{81718}$ The tool contains seven different items each item with a 0,1 or 2 , with a maximum total score of 10 for each paper. A score of 9-10 determines a very good study, 7-8 is a good study, 5-6 is satisfactory 
and $0-4$ is unsatisfactory. Second, the Critical Appraisal Skills Programme was used for studies with a qualitative design. ${ }^{19}$ This tool contains 10 questions concerned with the appropriateness of the research methodology, methods, recruitment strategy and rigour of the data analysis. Each question is answered 'yes' if 'clear, adequate information is described' and 'no' if there is 'insufficient information described to answer the question'.

\section{Analysis and synthesis}

This review used a descriptive narrative synthesis method looking for common themes and presented in a narrative format. The variation in the populations and measurement tools used by the studies included shows their heterogeneity, which limited the possibility of conducting meta-analysis in the current review. Two independent reviewers (AA and LK) identified factors reported in the included studies as contributing to safety culture and coded these into different domains according to the Yorkshire Contributory Factors Framework (YCFF) ${ }^{20}$

\section{Theoretical framework: the YCFF}

The YCFF was developed from a systematic review of 95 papers that identified factors contributing to patient safety incidents internationally. ${ }^{20}$ The YCFF categorises the factors into different domains: situational factors, local working conditions, latent / organisational factors, latent external factors and general factors (described in detail in the findings section). ${ }^{21} 22$ Although the YCFF was created to capture factors contributing to specific patient safety incidents, it was used in this review to categorise factors contributing to patient safety culture more broadly. This is consistent with previous approaches where the framework was used as an analysis tool to proactively identify factors contributing to patient safety performance at both individual and organisational levels. ${ }^{20}$

\section{Patient and public involvement}

No patients were involved in this review.

\section{RESULTS}

From the 419 papers identified by searches, 14 met the criteria for inclusion in this review (figure 1).

\section{General characteristics of included studies}

Twelve studies adopted a cross-sectional survey design. ${ }^{23-34}$ Two used a qualitative approach, employing focus group interviews for data collection method. ${ }^{35} 36$ Although all of the cross-sectional studies used a self-administered questionnaire as the data collection instrument, they differed in the types of the questionnaire used to collect information on factors influencing patient safety. Seven studies $^{23} 25-27303134$ used the Hospital Survey on Patient Safety Culture, two studies ${ }^{24} 28$ used the Safety Attitude Questionnaire and two studies ${ }^{29}{ }^{32}$ used the Safety Climate Scale. All of these tools were reported as valid and reliable and are used widely to assess the patient safety culture in

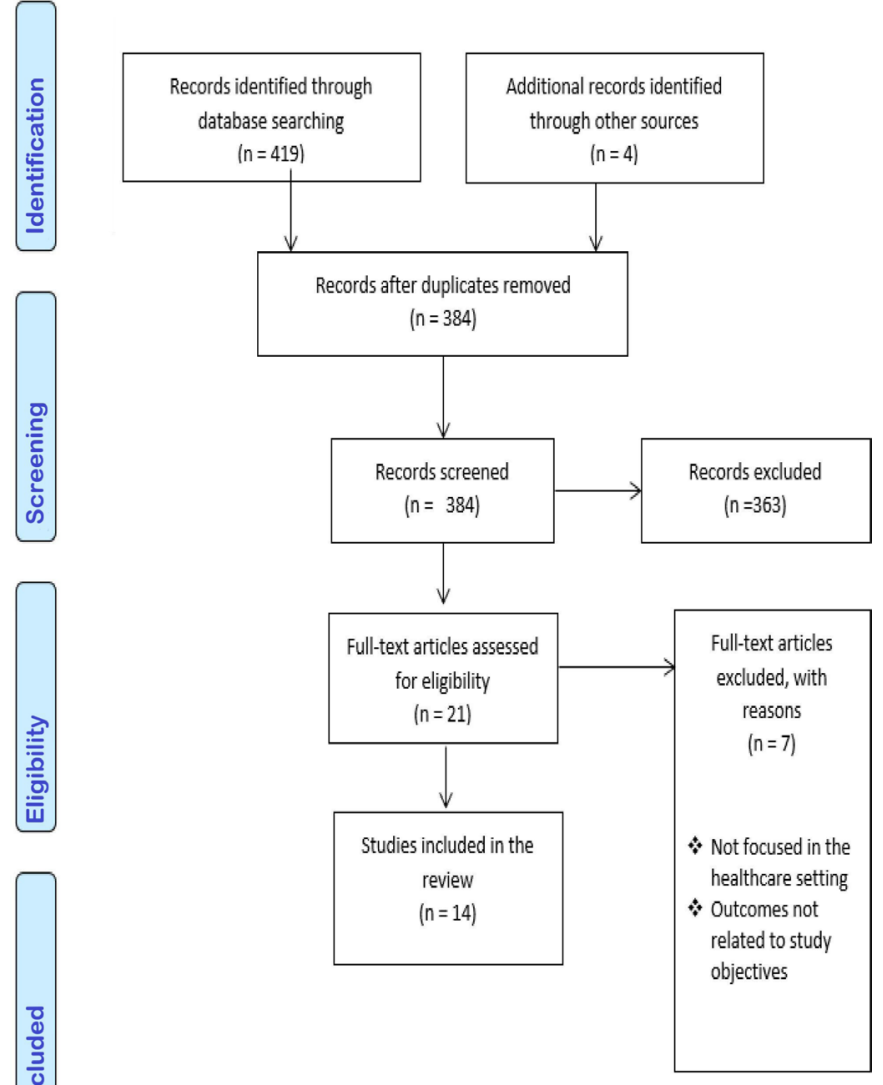

Figure 1 Preferred Reporting Items for Systematic Reviews and Meta-Analyses flow diagram shows details of our process and selection of studies including numbers of studies excluded with reasons.

healthcare settings. ${ }^{37-39}$ In one study, ${ }^{33}$ the authors developed a questionnaire based on the literature.

Six studies focused solely on nurses working in hospital departments ${ }^{2327-293136}$ and eight studies involved a range of different healthcare professionals including nurses, physicians, technicians, pharmacists and managers. ${ }^{24-26} 30$ 32-35 The sample sizes in the included studies ranged from 23 to 2592 participants. None of the studies were conducted in a primary healthcare setting; all studies were carried out in different hospital settings in Saudi Arabia. None of the studies included patients or families as participants.

\section{Quality of studies}

Overall, the majority of studies were appraised as being of good quality (see online supplemental appendix $3,4)$. There were some methodological issues related mainly to the selection of the participants and representativeness of the target population, which makes it difficult to judge their populations and whether they were representative enough of the target population. ${ }^{23} 27$ This might increase the potential for selection bias or limit the representativeness of the sample. ${ }^{40}$ None of these studies $^{23} 2427283334$ provide justification for their sample calculations and whether they were based on power calculations or not. Moreover, one of the studies was criticised for the validity of the questionnaire because it was 


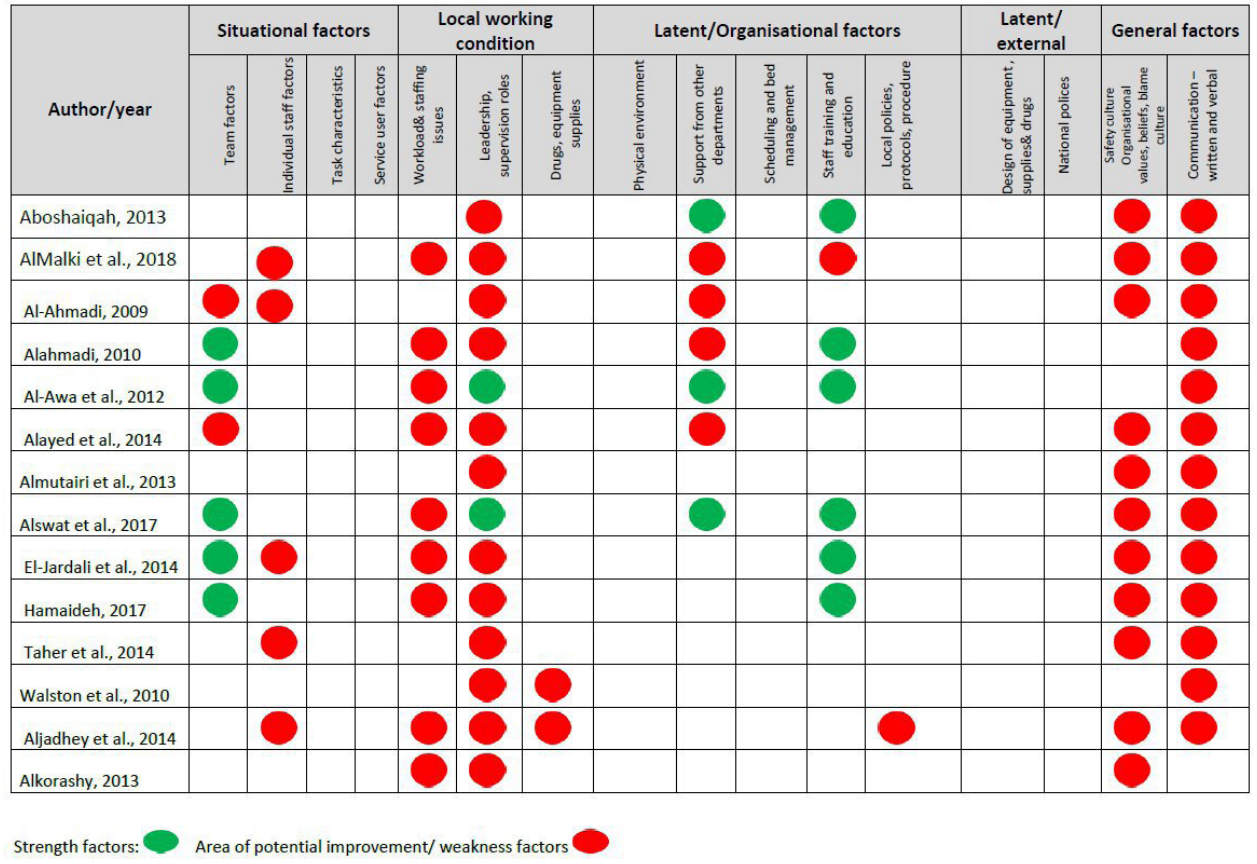

Figure 2 Factors identified as contributing to patient safety culture, organised under Yorkshire Contributory Factors Framework (YCFF) domain headings, by study. This figure shows that all factors identified from 14 studies included in this review were coded into different domains according to the YCFF. Colour coded to indicate factors identified as strengths and weaknesses in each study. Weakness factors (shown in red) indicate that factors need an improvement. In contrast, strengths factors (shown in green) indicate that factors reported as good. Some areas were left blank, which indicate that no factors were identified from studies related to these headings.

developed specifically for the study and no justification was given of the measures used to test their validity and reliability. ${ }^{33}$

\section{Key findings}

Factors identified as contributing to patient safety culture were organised under YCFF domain headings and colour coded to indicate factors identified as strengths and weaknesses in each study (figure 2). Weakness factors (shown in red in figure 2) identified in this review appeared across most of the YCFF domains. In contrast, strengths factors (shown in green in figure 2) appeared only in three domains: situational factors, local working conditions and latent/organisational factors.

\section{Situational factors}

Situational factors relate to characteristics of people in the workplace setting and aspects influencing the workplace, including team factors, individual staff factors, patient factors/services user factors and task characteristic factors. Good teamwork within a unit was reported as a strength factor 2627303134 because healthcare professionals perceived it as enhancing patient safety culture. However, other studies ${ }^{25} 2628$ found teamwork across hospital units and multidisciplinary teams to be an area requiring potential improvement, due to deficits in interprofessional teamwork across disciplines, which may compromise patient care. In terms of individual staff characteristics, four of the studies ${ }^{24-2632}$ reported that staff had a negative attitude towards patient safety. This was especially the case with perceptions of hospital management and working conditions. Rushed work, different languages and cultural diversity were reported to affect staff's ability to discuss patient safety concerns due to inadequate time or language difficulties. ${ }^{30}$ Multilingualism and cultural diversity were identified as increasing influence on the occurrence of medication errors, especially when conveying verbal orders, ${ }^{34}$ consequently impacting the perception of safety culture.

The task characteristic factors and services users' factors are concerned with specific issues such as abnormal physiology or aggression, which make individuals vulnerable to errors. However, none of the data extracted aligned with these elements of the framework.

\section{Local working conditions}

Local working conditions refer to whether or not the work environment conditions support patient safety and create a safe environment. The term broadly covers staffing issues and workload, leadership and equipment supply. One of the most common factors influencing patient safety culture identified in this review is leadership and supervision. These were highlighted by all but two ${ }^{27} 34$ of the included studies as weakness factors that required further improvements. It was perceived that there was a lack of effective leadership, as leaders failed to promote staff support or encouragement, provide feedback or create a sustainable safety culture that would proactively minimise errors. ${ }^{23} 293236$ Heavy workload, staff shortages, 
insufficient skills and poor staff to patient ratios were also reported as weakness factors that hindered positive patient safety cultures. ${ }^{25-28} 3031$ 34-36

Inadequacy of equipment and supplies were also identified as issues that hindered optimal patient safety. For example, limited use of technology, especially with regard to prescribing medications and relying on handwriting, may increase the risk of medication errors. ${ }^{33} 35$

\section{Latent/organisational factors}

These factors relate to the physical environment, support from central functions, scheduling and bed management, training and education, and local policies and procedures. However, from the included studies, we identified strength and weakness factors that fell within only three of the categories of latent organisational factors (figure 2). In relation to staff training and education, organisational learning/continuous improvements were reported as strength factors in the majority of studies, due to the ability of healthcare organisations to create an environment supportive of learning that improves knowledge and skills.

In relation to support from other departments, several aspects of poor organisational structure and approaches were identified as weaknesses to support patient safety in the workplace: poor administrative support, suboptimal management of patient safety concerns, lack of interdepartmental collaboration, absent logistic support and limited technology use. Other factors are limited availability of patient safety standards/guidelines due to poor dissemination in the workplace that lead to inappropriate prioritising of patient safety issues effectively. ${ }^{24-26} 2835$

\section{Latent /external factors}

These factors relate to the design of equipment, supplies and drugs, and national policies. However, no studies reported data aligning with these categories of the YCFF.

\section{General factors}

We identified two general factors relating to communication systems and safety culture/awareness within organisations themselves, which were reported as directly affecting patient safety.

\section{Communications}

The availability and effectiveness of processes and systems within organisations for exchanging information between staff, patient, groups, departments and services include both written and verbal communications. Poor communication was the most frequently reported weakness factor, besides blame culture and poor leadership (figure 2). Communication breakdowns were recognised in different areas including among hospitals departments, during patient handoffs, and between patients and healthcare professionals. ${ }^{2535}$ In addition, a lack of available and functioning reporting systems was also identified as limiting ability or willingness to reporting incidents and learn from errors. ${ }^{2533}$
Table 1 Summary of factors identified (strengths and weakness)

\begin{tabular}{|c|c|}
\hline $\begin{array}{l}\text { Area of potential } \\
\text { improvement/weakness }\end{array}$ & Strengths \\
\hline - Ineffective leadership & $\begin{array}{l}\text { Collaborative teamwork } \\
\text { within hospitals units }\end{array}$ \\
\hline - Blame culture & $\begin{array}{l}\text { Clear feedback and } \\
\text { communications about } \\
\text { errors }\end{array}$ \\
\hline $\begin{array}{l}\text { High workload/ } \\
\text { inadequate staff }\end{array}$ & $\begin{array}{l}\text { Realistic manager } \\
\text { expectations and supportive } \\
\text { actions promoting patient } \\
\text { safety }\end{array}$ \\
\hline - Poor communications & $\begin{array}{l}\text { Effective organisational } \\
\text { learning/staff education and } \\
\text { continuous improvement }\end{array}$ \\
\hline $\begin{array}{l}\text { Lack of teamwork/ } \\
\text { collaboration across } \\
\text { hospital units }\end{array}$ & \\
\hline $\begin{array}{l}\text { Lack of reporting } \\
\text { systems }\end{array}$ & \\
\hline $\begin{array}{l}\text { Low staff experience, } \\
\text { low staff competence }\end{array}$ & \\
\hline $\begin{array}{l}\text { Communications } \\
\text { gaps between } \\
\text { healthcare institutions/ } \\
\text { professionals/patients }\end{array}$ & \\
\hline $\begin{array}{l}\text { Inadequate resources/ } \\
\text { equipment }\end{array}$ & \\
\hline
\end{tabular}

This table shows summary of all factors identified in this review which categorised as (strengths and weakness) factors.

\section{Awareness of safety culture}

The perception of patient safety culture and awareness about safety issues among individuals was identified by most studies in this review as a factor that weakened patient safety culture. ${ }^{23-25} 28303234$ Particularly, awareness of a safety culture varied among healthcare professionals and was influenced by staff position, experience, cultural background and language. For instance, one study found that nurses had a higher perception than physicians of the positive safety climate in their organisations. ${ }^{32} \mathrm{~A}$ blame culture/punitive response to errors was reported in the majority of the studies (figure 2) in this review as a weakness factor that negatively influenced the safety culture and the reporting of incidents. Table 1 provides an overall summary of the factors identified (strengths and weaknesses).

\section{SUMMARY OF FINDINGS Discussion}

This review has focused on identifying the factors contributing to patient safety culture from different stakeholders' perspectives in the context of hospitals in Saudi Arabia. The evidence identified in this review shows that some 
factors contributed in a facilitative way, whereas others were detrimental in helping to establish a positive patient safety culture within the hospitals. Interestingly, the number of areas requiring improvement outweighed the reported strengths. This highlights patient safety in Saudi Arabian hospitals as a priority area for improvement and indicates the key gaps and weaknesses in the patient safety culture in the Saudi Arabia healthcare system.

Leadership, blame culture, workload/staffing issues and communication were the factors most frequently reported as hindering a positive safety culture. These findings are consistent with a previous systematic review, ${ }^{8}$ which found that blame culture and communication problems were serious issues facing healthcare systems in various Arab countries. Therefore, it could be argued that a blame culture is dominant in Arab countries' healthcare systems, including that of Saudi Arabia. This may be related to poor leadership and a lack of regulations supporting patient safety. ${ }^{8}$

Punitive approaches to errors are a common contributor to under-reporting of incidents, due to fear of punishment. ${ }^{41-43}$ Therefore, creating work environments that are supporting constructive feedback, learning from errors, encouraging speak up and establish accountable culture is essential to improve actions and responses following errors. ${ }^{44}$

Effective communication is integral to patient safety as it helps to facilitate the working of multidisciplinary teams. ${ }^{45}$ In this review, we found that the quality of communication in general was reported as poor and was perceived to inhibit a positive patient safety culture within organisations. These deficiencies in communication included poor communication among healthcare professionals, among hospital departments and between healthcare providers and patients (table 1). Different languages and cultures among nurses made the adoption of the optimal degree of communication difficult. ${ }^{22}$ This is probably explained by the workforce diversity in Saudi Arabian healthcare and the impact of the different languages and cultures on caregivers, which might hamper effective collaboration and communication. ${ }^{9}$ Failure to communicate well may also be related to poor leadership and leaders' inability to establish successful implementation strategies to support and establish effective communications channels. ${ }^{46}$

Furthermore, poor communication may be related to organisational infrastructure ${ }^{42}$ such as hospitals' capacity to provide effective systems/resources for communication, training, technical support and feedback to improve quality of care. ${ }^{47}$ There is an obvious lack of reporting systems in Saudi Arabia, ${ }^{32}$ which may reduce the voluntary reporting of incidents and the ability to learn from errors. ${ }^{42}$ Although this review identified that communication in general is one of the main factors contributing to positive patient safety culture, it is important to understand the role of communications gaps in hampering a positive patient safety culture and contributing to errors in the Saudi health context. Thus, more research is required to examine the structure and mechanisms of communication systems in order to investigate the barriers that affect patient safety.

A high workload, rushed work, an inadequate number of staff and long work hours were also identified in this review as factors requiring improvement. This is consistent with evidence that workload is a complex issue that directly affects patient safety, due to the staff's limited ability to provide adequate patient supervision, holistic care and decision making. ${ }^{48}$ High workload reduces attention/vigilance and increases distress from working under pressure. ${ }^{48} 49$ A high workload leads to fatigue among nurses, which is linked to physical and cognitive impairment, that in turn increases the risk of medication errors. ${ }^{45}$ An observational study in Finland investigated the impact of nurses' daily workload on patient safety and reported that a high workload led to an increase in patient safety incidents of up to $30 \%$ and a rise in mortality rates of up to $40 \%$. $^{50}$

It is worth noting that the level of organisational support for patient safety culture and teamwork collaboration were reported as both strength factors and areas that needed improvement. This variation is related to differences in organisational policies, rules, strategies and general infrastructure that supports patient safety. ${ }^{51}$ Variation in teamwork within units, multidisciplinary teams and hospital departments may be related to the lack of a standardised system including IT and communication system that facilitates staff interactions and engagement for patient safety. ${ }^{47} 51$ Teamwork and communication are regarded as substantial in modern healthcare delivery that are based on a multidisciplinary team's performance rather than an individual's role. ${ }^{52}$ Therefore, decision makers in the healthcare system in Saudi Arabia should value the importance of consensus in patient safety standards and taxonomy as it can facilitate the successful implementation of high-level patient safety and quality of care. From a research perspective, this highlights the fact that the contexts surrounding these issues can be different and they can therefore be facilitative or not. It follows that it would also be worth conducting further research on the contexts that 'trigger' mechanisms leading to positive patient safety cultures.

Organisational learning/continuous improvement was reported as a strength that actively enhanced patient safety culture improvement initiatives. Adopting a learning culture where staff could openly share their experiences, successes and challenges were seen as central to achieving a safe and high quality of healthcare, ${ }^{153}$ increasing opportunities for individuals and organisations to use failures as learning opportunities, providing feedback following incident analysis and establishing the usefulness of improvement initiatives. ${ }^{153}$ Thus, learning systems and continuous improvements in Saudi healthcare organisations should motivate individuals to learn from previous mistakes and establish development approaches that address individuals' needs to proactively prevent patient harm. Moreover, learning from patient experience and feedback is also another suitable tool that provides an 
in-depth understanding of patient safety threats. ${ }^{545}$ It is therefore suggested that such initiatives of involvement of patient/family in safety approaches be implemented in practice.

The review found no results or studies assessing patient perspectives in regard to patient safety in Saudi Arabian healthcare organisations. None of the studies measured patients' experiences, perspectives or concerns. This is not to say that these perspectives are not sought as part of the culture of patient safety in Saudi Arabia but there is a lack of evidence to demonstrate their widespread involvement in research in this area. Encouraging and supporting patient and family participation in healthcare safety and patient safety initiatives is increasing globally and is central to the prevention of errors and to guide improvement strategies. ${ }^{5657}$

\section{Limitations}

This systematic review excluded non-English publications, which may create publication bias and mean that some relevant papers were missed. ${ }^{54}$ Additionally, due to the lack of studies conducted in primary healthcare, the generalisability of these findings may be limited to hospital settings only. The majority of the included studies were cross-sectional surveys that used different measuring tools; this may create self-reporting bias. ${ }^{40}$ Moreover, these cross-sectional studies failed to provide details of the complex nature of the factors contributing to patient safety culture. Only two studies used a qualitative approach, which can provide in-depth data about the status of the patient safety culture in some healthcare settings. However, due to the poor methodological quality of one of the qualitative studies (see online supplemental appendix 4), the findings should be treated with caution. Although the YCFF provides useful classifications and enables clear description and categorisation of factors affecting patient safety culture, using other theoretical frameworks may have identified more contributory.

\section{Relevance to practice and recommendations}

From a practice perspective, there is no doubt that creating and maintaining a positive patient safety culture is linked to safe and effective healthcare practices. Therefore, this review confirms that patient safety initiatives and quality improvement are essential in healthcare systems in Saudi Arabia. To enhance patient safety and reduce potential errors, a standardised governmental improvement initiative is recommended to enhance a positive patient safety culture. Priority for improvement should be communicating and transforming information, addressing blame culture and enhancing leadership and human resources.

Further research is required to identify barriers to either the individual or organisation that may reduce the practical application of a positive patient safety culture. Similarly, this review demonstrates that patient and family perspectives and experiences of safety culture should be investigated.

\section{CONCLUSION}

This review identifies several key factors that contribute to patient safety culture in Saudi Arabia where these can be categorised into strength and weakness factors (or areas for potential improvement). The review shows that only healthcare professionals' perspectives have been included in surveys of patient safety culture in Saudi Arabia to date. Thereby patient perspectives and feedback are required as these are considered globally as integral to hospital quality improvement processes. Policy-makers in the Saudi healthcare system should pay attention to the factors that may support the implementation of a positive patient safety culture, especially establishing a blame-free ethos, improving communications and leadership capacity, learning from errors and involving patient perspectives in safety initiatives.

Acknowledgements The authors would like to thank Saudi Cultural Bureau in London, UK for sponsoring this study and librarian at the University of Glasgow for valuable support during the database search.

Contributors All authors contributed to the development of the study protocol. LK and EC helped AA in designing the research strategy and selecting studies for inclusion. AA carried out the search and extracted the data under supervision of LK and EC. Screening and assessment of the quality of the included studies were conducted by two independent reviewers (AA and LK), with disagreements settled by EC. Data analysis was carried out under the supervision of LK and EC. The manuscript was written by $A A$ and then revised by LK and EC.

Funding This review is part of the $\mathrm{PhD}$ project of Mr Abdulmajeed Albalawi, which is funded by the Royal Embassy of Saudi Arabia in London. Award/grant number: Not applicable.

Competing interests None declared.

Patient consent for publication Not required.

Provenance and peer review Not commissioned; externally peer reviewed.

Data availability statement All data relevant to the study are included in the article or uploaded as supplemental information.

Supplemental material This content has been supplied by the author(s). It has not been vetted by BMJ Publishing Group Limited (BMJ) and may not have been peer-reviewed. Any opinions or recommendations discussed are solely those of the author(s) and are not endorsed by BMJ. BMJ disclaims all liability and responsibility arising from any reliance placed on the content. Where the content includes any translated material, BMJ does not warrant the accuracy and reliability of the translations (including but not limited to local regulations, clinical guidelines, terminology, drug names and drug dosages), and is not responsible for any error and/or omissions arising from translation and adaptation or otherwise.

Open access This is an open access article distributed in accordance with the Creative Commons Attribution Non Commercial (CC BY-NC 4.0) license, which permits others to distribute, remix, adapt, build upon this work non-commercially, and license their derivative works on different terms, provided the original work is properly cited, appropriate credit is given, any changes made indicated, and the use is non-commercial. See: http://creativecommons.org/licenses/by-nc/4.0/.

ORCID iD

Abdulmajeed Albalawi http://orcid.org/0000-0002-2894-2716

\section{REFERENCES}

1 Morello RT, Lowthian JA, Barker AL, et al. Strategies for improving patient safety culture in hospitals: a systematic review. BMJ Qual Saf 2013;22:11-18.

2 Health and Safety Commission Advisory Committee on the Safety of Nuclear Installations. Organizing for safety: third report of the ACSNI study group on human factors Sudbury. HSE Books, 1993.

3 Ulrich B, Kear T. Patient safety and patient safety culture: foundations of excellent health care delivery. Nephrol Nurs $J$ 2014;41:447-59. 
4 World Health Organization. 10 facts on patient safety, 2018. Available: http://www.who.int/features/factfiles/patient_safety/en/

5 Bari A, Khan RA, Rathore AW. Medical errors; causes, consequences, emotional response and resulting behavioral change. Pak J Med Sci 2016;32:523.

6 DiCuccio MH. The relationship between patient safety culture and patient outcomes: a systematic review. J Patient Saf 2015:11:135-42.

7 Camargo CA, Tsai C-L, Sullivan AF, et al. Safety climate and medical errors in 62 us emergency departments. Ann Emerg Med 2012;60:555-63.

8 Elmontsri M, Almashrafi A, Banarsee R, et al. Status of patient safety culture in Arab countries: a systematic review. BMJ Open 2017;7:e013487.

9 Almutairi KM. Culture and language differences as a barrier to provision of quality care by the health workforce in Saudi Arabia. Saudi Med J 2015;36:425-31.

10 Ala'a ZM, Aljasser IA, Sasidhar B. Barriers to reporting medication administration errors among nurses in an accredited hospital in Saudi Arabia. J Econ Manage Trade 2016:1-13.

11 Samarkandi A. Status of medical liability claims in Saudi Arabia. Ann Saudi Med 2006;26:87-91.

12 Ghaffar UB, Ahmed SM, Faraz A. A review of the frequency of medical error in Saudi Arabia: an emerging concern. Jebmh 2015;2:8692-5.

13 Al Wahabi S, Farahat F, Bahloul AY. Prevalence and preventability of sentinel events in Saudi Arabia: analysis of reports from 2012 to 2015. East Mediterr Health J 2017;23:492.

14 Christiaans-Dingelhoff I, Smits M, Zwaan L, et al. To what extent are adverse events found in patient records reported by patients and healthcare professionals via complaints, claims and incident reports? BMC Health Serv Res 2011;11:49.

15 Lawton R, O'Hara JK, Sheard L, et al. Can staff and patient perspectives on hospital safety predict harm-free care? an analysis of staff and patient survey data and routinely collected outcomes. BMJ Qual Saf 2015;24:369-76.

16 Wells GA, Tugwell P, O'Connell D, et al. The Newcastle-Ottawa scale (NOS) for assessing the quality of nonrandomized studies in metaanalyses, 2015

17 Modesti PA, Reboldi G, Cappuccio FP, et al. Panethnic differences in blood pressure in Europe: a systematic review and meta-analysis. PLoS One 2016;11:e0147601.

18 Herzog R, Álvarez-Pasquin MJ, Díaz C, et al. Are healthcare workers' intentions to vaccinate related to their knowledge, beliefs and attitudes? A systematic review. BMC Public Health 2013;13:154

19 Critical Appraisal Skills Programme. CASP qualitative research checklist, 2016. Available: http://www.casp-uk.net/casp-toolschecklists

20 Lawton R, McEachan RRC, Giles SJ, et al. Development of an evidence-based framework of factors contributing to patient safety incidents in hospital settings: a systematic review. BMJ Qual Saf 2012;21:369-80.

21 Hernan AL, Giles SJ, Fuller J, et al. Patient and carer identified factors which contribute to safety incidents in primary care: a qualitative study. BMJ Qual Saf 2015;24:583-93.

22 Polisena J, Gagliardi A, Urbach D, et al. Factors that influence the recognition, reporting and resolution of incidents related to medical devices and other healthcare technologies: a systematic review. Syst Rev 2015:4:37.

23 Aboshaiqah AE, Baker OG. Assessment of nurses' perceptions of patient safety culture in a Saudi Arabia hospital. J Nurs Care Qual 2013;28:272-80.

24 Al Malki A, Endacott R, Innes K. Health professional perspectives of patient safety issues in intensive care units in Saudi Arabia. J Nurs Manag 2018;26:209-18.

25 Al-Ahmadi TA. Measuring patient safety culture in Riyadh's hospitals: a comparison between public and private hospitals. J Egypt Public Health Assoc 2009;84:479-500.

26 Alahmadi HA. Assessment of patient safety culture in Saudi Arabian hospitals. Qual Saf Health Care 2010;19:e17-e

27 Al-Awa B, Al Mazrooa A, Rayes O, et al. Benchmarking the postaccreditation patient safety culture at King Abdulaziz university hospital. Ann Saudi Med 2012;32:143-50.

28 Alayed AS, Lööf H, Johansson U-B. Saudi Arabian ICU safety culture and nurses' attitudes. Int J Health Care Qual Assur 2014;27:581-93.

29 Almutairi AF, Gardner G, McCarthy A. Perceptions of clinical safety climate of the multicultural nursing workforce in Saudi Arabia: a cross-sectional survey. Collegian 2013;20:187-94.
30 El-Jardali F, Sheikh F, Garcia NA, et al. Patient safety culture in a large teaching hospital in Riyadh: baseline assessment, comparative analysis and opportunities for improvement. BMC Health Serv Res 2014; $14: 122$

31 Hamaideh SH. Mental health nurses' perceptions of patient safety culture in psychiatric settings. Int Nurs Rev 2017;64:476-85.

32 Taher S, Hejaili F, Karkar A, et al. Safety climate in dialysis centers in Saudi Arabia: a multicenter study. J Patient Saf 2014;10:101-4.

33 Walston SL, Al-Omar BA, Al-Mutari FA. Factors affecting the climate of hospital patient safety: a study of hospitals in Saudi Arabia. Int $J$ Health Care Qual Assur 2010;23:35-50.

34 Alswat K, Abdalla RAM, Titi MA, et al. Improving patient safety culture in Saudi Arabia (2012-2015): trending, improvement and benchmarking. BMC Health Serv Res 2017;17:516.

35 Aljadhey H, Mahmoud MA, Hassali MA, et al. Challenges to and the future of medication safety in Saudi Arabia: a qualitative study. Saudi Pharm J 2014;22:326-32.

36 Alkorashy HAE. Factors shaping patient safety management in the middle East hospitals from nursing perspective: a focus group study. Middle-East J Sci Res 2013;15:1375-84.

37 Najiar S, Hamdan M, Baillien E, et al. The Arabic version of the hospital survey on patient safety culture: a psychometric evaluation in a Palestinian sample. BMC Health Serv Res 2013;13:193.

38 Elsous A, Akbarisari A, Rashidian A, et al. Psychometric properties of an Arabic safety attitude questionnaire (short form 2006). Oman Med $J$ 2017:32:115-23.

39 Kho ME, Carbone JM, Lucas J, et al. Safety climate survey: reliability of results from a multicenter ICU survey. Qual Saf Health Care 2005:14:273-8.

40 Polit DF, Beck CT. Nursing research: generating and assessing evidence for nursing practice. Philadelphia: Wolters Kluwer Health, 2017.

41 Waring JJ. Beyond blame: cultural barriers to medical incident reporting. Soc Sci Med 2005;60:1927-35.

42 Hartnell N, MacKinnon N, Sketris I, et al. Identifying, understanding and overcoming barriers to medication error reporting in hospitals: a focus group study. BMJ Qual Saf 2012;21:361-8.

43 Pfeiffer Y, Manser T, Wehner T. Conceptualising barriers to incident reporting: a psychological framework. Qual Saf Health Care 2010;19:e60-e

44 Tigard DW. Taking the blame: appropriate responses to medical error. $J$ Med Ethics 2019;45:101-5.

45 Leonard M, Graham S, Bonacum D. The human factor: the critical importance of effective teamwork and communication in providing safe care. Qual Saf Health Care 2004;13:i85-90.

46 Connerley ML, Pedersen PB. Leadership in a diverse and multicultural environment: developing awareness, knowledge, and skills. Sage Publications, 2005.

47 Dingley C, Daugherty K, Derieg MK, et al. Improving patient safety through provider communication strategy enhancements, 2008.

48 Aiken LH, Clarke SP, Sloane DM, et al. Hospital nurse staffing and patient mortality, nurse burnout, and job dissatisfaction. JAMA 2002:288:1987-93.

49 Holden RJ, Scanlon MC, Patel NR, et al. A human factors framework and study of the effect of nursing workload on patient safety and employee quality of working life. BMJ Qual Saf 2011;20:15-24.

50 Fagerström L, Kinnunen M, Saarela J. Nursing workload, patient safety incidents and mortality: an observational study from Finland. BMJ Open 2018;8:e016367.

51 Firth-Cozens J. Organisational trust: the keystone to patient safety. Qual Saf Health Care 2004;13:56-61.

52 Gharaveis A, Hamilton DK, Pati D. The impact of environmental design on teamwork and communication in healthcare facilities: a systematic literature review. HERD 2018;11:119-37.

53 Edmondson AC. Learning from failure in health care: frequent opportunities, pervasive barriers. Qual Saf Health Care 2004;13:ii3-9.

54 Ward JK, Armitage G. Can patients report patient safety incidents in a hospital setting? A systematic review. BMJ Qual Saf 2012;21:685-99.

55 O'Hara JK, Reynolds C, Moore S, et al. What can patients tell us about the quality and safety of hospital care? findings from a UK multicentre survey study. BMJ Qual Saf 2018;27:673-82.

56 Severinsson IE, Holm AL. Patient's role in their own safety-a systematic review of patient involvement in safety, 2015.

57 Vaismoradi M, Jordan S, Kangasniemi M. Patient participation in patient safety and nursing input - a systematic review. J Clin Nurs 2015;24:627-39. 